Pacific Journal of Mathematic 


\section{AN EXTENDED FORM OF THE MEAN-ERGODIC THEOREM}

\section{Lynn C. Kurtz and Don H. Tucker}

Suppose $X$ is a reflexive Banach space and $V$ is a continuous linear operator in $X$ such that $\left\|V^{n}\right\| \leqq M$ for some $M(n=0,1,2, \ldots)$. If $N$ is the null space of $I-V$ and $R$ is the closure of the range of $I-V$, then the mean-ergodic theorem states that

$$
\lim _{n \rightarrow \infty} \frac{\left(I+V+\cdots+V^{n-1}\right) x}{n}=P x,
$$

where $P$ is the projection associated with $N$ and $R$; the convergence is in the norm of $X$. This is pointwise $C_{1}$-summability of the sequence $\left\{V^{k}\right\}_{k=0}^{\infty}$ to $P$, and it suggests a similar theorem for more general Hausdorff summability methods. The purpose of this note is to demonstrate a wide class of operatorvalued Hausdorff summability methods which contain the sequence $\left\{V^{k}\right\}_{k=0}^{\infty}$ in their wirkfelder and sum it to certain transforms of the projection operator $P$. This result shows much more clearly the sense in which convergence actually has meaning for such a sequence $\left\{V^{k}\right\}_{k=0}^{\infty}$.

Denote by $C(X)$ the space of $X$-valued continuous functions on $[0,1]$ and by $T_{1}$ the bounded linear transformation from $C(X)$ into $X$ given by $T_{1}(f)=\int_{0}^{1} f(t) d t$. The mean-ergodic theorem states that

$$
T_{1}\left(\sum_{k=0}^{n}\left(\begin{array}{l}
n \\
k
\end{array}\right)\left(t^{k}(1-t)^{n-k} V^{k} \cdot x\right) \underset{n \rightarrow \infty}{\longrightarrow} T_{1}(P \cdot x) .\right.
$$

In this setting, the main theorem of this paper states a much stronger type of convergence; namely, that for any bounded linear operator $T$ from $C(X)$ into a Banach space $Y$ such that the generating function for $T$ is continuous at 0 and 1 , it is true that

$$
T\left(\sum_{k=0}^{n}\left(\begin{array}{l}
n \\
k
\end{array}\right) t^{k}(1-t)^{n-k} V^{k} \cdot x\right) \underset{n \rightarrow \infty}{\longrightarrow} T(P \cdot x) .
$$

In general one cannot expect much in the way of further relaxations on the operators $T$, i.e., on the functions which generate such operators. For example if the condition of continuity at 1 is removed, then this allows a generating function $K(t)=0$ for $t<1, K(1)=1$ and this generates the Hausdorff method corresponding to ordinary convergence. In general the sequence $\left\{V^{k} \cdot x\right\}$ does not converge.

A nice presentation of the mean ergodic theorem as stated above is to be found in Lorch [2, pp. 54-56]. Suppose $Y$ is a Banach space 
and $\mu=\left\{\mu_{k}\right\}_{k=0}^{\infty}$ is a sequence of elements of $B[X, Y]$ such that the Hausdorff method $H=\rho \mu \rho$ generated by $\mu$ is regular relative to some $L \in B[X, Y]$. (See [1] for notation and terminology. Reference 8 in [1] is reference [3] of this paper.) It follows from [1] that there exists a function $K$ on $[0,1]$ with values in $B^{+}[X, Y]$ such that $K$ satisfies the Gowurin $\omega$-property,

$$
K(0)=0, K(1)=L \quad \text { and } \quad \mu_{n}=\int_{0}^{1} d K(t) \cdot t^{n} \quad \text { for } \quad n=0,1,2, \cdots
$$

THEOREM. If $K$ is continuous at $t=0$ and $t=1$, then $\left\{V^{k}\right\}_{k=0}^{\infty}$ is pointwise $H$-summable to $L P$, i.e., $H_{n}\left\{V^{k}\right\} \cdot x$ converges in the norm of $Y$ to $L P x$ for each $x \in X$.

The essential ingredient of the proof of the theorem is the following lemma.

LEMmA. If $\left\{s_{k}\right\}_{k=0}^{\infty}$ is a bounded sequence of elements of a linear normed space $S$ and $0<a \leqq t \leqq b<1$, then

$$
\|\left.\sum_{k=0}^{n}\left(\begin{array}{c}
n \\
k
\end{array}\right) t^{k}(1-t)^{n-k}\left(s_{k}-s_{k+1}\right)\right|_{S}
$$

converges uniformly to zero for $t \in[a, b]$.

Proof of the lemma. ${ }^{1}$ Suppose $\left\|s_{k}\right\| \leqq N^{\prime}$ for $k=0,1,2, \cdots$, then set

$$
\begin{aligned}
A_{n}(t)= & \sum_{k=0}^{n}\left(\begin{array}{l}
n \\
k
\end{array}\right) t^{k}(1-t)^{n-k}\left(s_{k}-s_{k+1}\right) \\
= & \sum_{k=1}^{n}\left[\left(\begin{array}{l}
n \\
k
\end{array}\right) t^{k}(1-t)^{n-k}-\left(\begin{array}{c}
n \\
k-1
\end{array}\right) t^{k-1}(1-t)^{n-k+1}\right] s_{k} \\
& +(1-t)^{n} s_{0}-t^{n} s_{n+1} \\
= & \sum_{k=1}^{n}\left(\begin{array}{c}
n \\
k
\end{array}\right) t^{k}(1-t)^{n-k}\left[1-\frac{k}{n-k+1} \cdot \frac{1-t}{t}\right] s_{k} \\
& +(1-t)^{n} s_{0}-t^{n} s_{n+1} \\
= & \frac{1}{t} \sum_{k=0}^{n}\left(\begin{array}{c}
n \\
k
\end{array}\right) t^{k}(1-t)^{n-k}\left[\frac{t-\frac{k}{n} \cdot \frac{n}{n+1}}{1-\frac{k}{n} \cdot \frac{n}{n+1}}\right] s_{k}-t^{n} s_{n+1} \cdot \\
\left\|A_{n}(t)\right\|_{s} \leqq & \frac{1}{t}\left\|\sum_{k=0}^{n}\left(\begin{array}{l}
n \\
k
\end{array}\right) t^{k}(1-t)^{n-k}\left[\frac{t-\frac{k}{n} \cdot \frac{n}{n+1}}{1-\frac{k}{n} \cdot \frac{n}{n+1}}\right] s_{k}+t^{n}\right\| s_{n+1} \|
\end{aligned}
$$

1) The proof presented here is incorrect. See part 2 for a corrected proof. 
where $0<a \leqq t \leqq b<1$, and hence

$$
\left\|A_{n}(t)\right\|_{s} \leqq \frac{N^{\prime}}{t} \sum_{k=0}^{n}\left(\begin{array}{c}
n \\
k
\end{array}\right) t^{k}(1-t)^{n-k} \frac{\left|t-\frac{k}{n} \cdot \frac{n}{n+1}\right|}{1-\frac{k}{n} \cdot \frac{n}{n+1}}+t^{n} \cdot N^{\prime} .
$$

Let $f_{n}(x, t)$ be given by

$$
f_{n}(x, t)=\left|x-t \cdot \frac{n}{n+1}\right| /\left(1-t \cdot \frac{n}{n+1}\right)
$$

and $C_{n}(t)$ by

$$
C_{n}(t)=\left.\frac{1}{t} B_{n}\left[f_{n}(x, t)\right]\right|_{x=t}
$$

where $B_{n}$ denotes the $n$-th Bernstein polynomial. The above inequality may now be written

$$
\left\|A_{n}(t)\right\|_{S} \leqq N^{\prime}\left|C_{n}(t)\right|+t^{n} \cdot N^{\prime}
$$

and the second term converges uniformly to zero for $t \in[a, b]$.

The first term is treated as follows. By a direct calculation it can be shown that for each $x \in[0, b]$, the collection $\left\{f_{n}(x, t)\right\}$ is equiuniformly continuous in $t$ for $t \in[0, b]$, that is to say, if $\varepsilon>0$, then there exists $\delta>0$ such that $\left|f_{n}(x, s)-f_{n}(x, t)\right|<\varepsilon / 2$ for all $s, t \in[0, b]$ such that $|s-t|<\delta$ and for all $n$.

Consider a fixed $t \in[0, b]$ and set $A=\{k:|k / n-t|<\delta\}$ and $B=$ $\{0,1, \cdots, n\}-A$. Then

$$
\begin{aligned}
& \left|B_{n}\left[f_{n}(x, t)\right]-f_{n}(x, t)\right| \\
\leqq & \left.\left(\sum_{A}+\sum_{B}\right) \mid\left(\begin{array}{l}
n \\
k
\end{array}\right) t^{k}(1-t)^{n-k}\left\{\frac{x-\frac{k}{n} \cdot \frac{n}{n+1}}{1-\frac{k}{n} \cdot \frac{n}{n+1}}\right\}-f_{n}(x, t)\right\} \mid \\
\sum_{A} \leqq & \sum_{k=0}^{n}\left(\begin{array}{c}
n \\
k
\end{array}\right) t^{k}(1-t)^{n-k} \cdot \frac{\varepsilon}{2}=\frac{\varepsilon}{2} .
\end{aligned}
$$

Set $Q=\max _{0 \leqq t, x \leqq b} f_{n}(x, t)$ for $n=0,1,2, \cdots$ and the second term can be treated as follows:

$$
\sum_{B} \leqq 2 Q \sum_{B}\left(\begin{array}{l}
n \\
k
\end{array}\right) t^{k}(1-t)^{n-k} \frac{(k-n t)^{2}}{n^{2} \delta^{2}} \leqq \frac{2 Q}{n^{2} \delta^{2}} \sum_{k=0}^{n}\left(\begin{array}{l}
n \\
k
\end{array}\right) t^{k}(1-t)^{n-k}(k-n t)^{2}
$$

which, as is well known, converges uniformly to zero for $t \in[0,1]$. Hence, there exists an integer $N_{0}$ such that $\sum_{B}<\varepsilon / 2$ for $n>N_{0}$ and further such that $\left|B_{n}\left[f_{n}(x, t)\right]-f_{n}(x, t)\right|<\varepsilon$ for $n>N_{0}$, both 
inequalities holding uniformly for $0 \leqq t \leqq b$. Collecting all these items together yields

$$
\lim _{n \rightarrow \infty} C_{u}(t)=\frac{1}{t} \frac{|t-t|}{1-t}=0
$$

uniformly for $t \in[a, b]$, and hence $\left\|A_{n}(t)\right\|_{S} \rightarrow 0$ uniformly on $[a, b]$.

Proof of the theorem. Let

$$
T_{n}=H_{n}\left\{V^{k}\right\}_{k=0}^{\infty}=\sum_{k=0}^{n}\left(\begin{array}{c}
n \\
k
\end{array}\right) \Delta^{n-k} \mu_{k} V^{k}=\int_{0}^{1} d K(t) \cdot\left[\sum_{k=0}^{n}\left(\begin{array}{c}
n \\
k
\end{array}\right) t^{k}(1-t)^{n-k} V^{k}\right] .
$$

Since $N, R$ is a complementary pair in $X$, it is sufficient to investigate the behavior of $T_{n}$ on each of these sets.

Suppose $f \in N$, i.e., $V f=f$, then

$$
\begin{aligned}
T_{n} f & =\int_{0}^{1} d K(t) \cdot\left[\sum_{k=0}^{n}\left(\begin{array}{l}
n \\
k
\end{array}\right) t^{k}(1-t)^{n-k} V^{k} f\right]=\int_{0}^{1} d K(t) \cdot\left[\sum_{k=0}^{n}\left(\begin{array}{l}
n \\
k
\end{array}\right) t^{k}(1-t)^{n-k} f\right] \\
& =\int_{0}^{1} d K(t) \cdot f=[K(1)-K(0)] f=L f=L P f .
\end{aligned}
$$

Now suppose $f \in R$ and $\varepsilon>0$, then there exists $g$ and $h$ such that $f=g-V g+h$ where $\|h\|<\varepsilon / 4\left[1+W_{0}^{1} K\right] M$. For this $f$,

$$
\begin{aligned}
T_{n} f= & \int_{0}^{1} d K(t) \cdot \sum_{k=0}^{n}\left(\begin{array}{c}
n \\
k
\end{array}\right) t^{k}(1-t)^{n-k}\left[V^{k} g-V^{k+1} g\right] \\
& +\int_{0}^{1} d K(t) \cdot \sum_{k=0}^{n}\left(\begin{array}{c}
n \\
k
\end{array}\right) t^{k}(1-t)^{n-k} V^{k} h=I+I I . \\
\|I I\|_{Y} & \leqq W_{0}^{1} K \cdot \max _{0 \leqq t \leqq 1}\left|\sum_{k=0}^{n}\left(\begin{array}{c}
n \\
k
\end{array}\right) t^{k}(1-t)^{n-k}\right| \max _{0 \leqq k \leqq n}\left\|V^{k} h\right\|_{X} \\
& \leqq W_{0}^{1} K \cdot M \cdot \varepsilon / 4\left[1+W_{0}^{1} K\right] M<\frac{\varepsilon}{4} \text { for all } n . \\
\|I\|_{Y} & =\|I\|_{Y * *}=\left\|\int_{0}^{a}+\int_{a}^{b}+\int_{b}^{1}\right\|_{Y * *} \\
& \leqq\left\|\int_{0}^{a}\right\|_{Y * *}+\left\|\int_{a}^{b}\right\|_{Y * *}+\left\|\int_{b}^{1}\right\|_{Y * *} .
\end{aligned}
$$

It is necessary to regard the norms on the right as $Y^{* *}$ norms because these integrals may exist only as elements in $Y^{* *}$ and not as elements in $Y$ (see the remarks following Theorem 1 [3, p. 950].)

$$
\| \int_{0}^{a} d K(t) \cdot\left[\sum_{k=0}^{n}\left(\begin{array}{l}
n \\
k
\end{array}\right) t^{k}(1-t)^{n-k}\left[V^{k} g-V^{k+1} g\right]\left\|_{Y * *} \leqq W_{0}^{a} K \cdot 2 M \cdot\right\| g \|_{X}\right.
$$

and

$$
\| \int_{b}^{1} d K(t) \cdot\left[\sum_{k=0}^{n}\left(\begin{array}{c}
n \\
k
\end{array}\right) t^{k}(1-t)^{n-k}\left[V^{k} g-V^{k+1} g\right]\left\|_{Y * *} \leqq W_{b}^{1} K \cdot 2 M \cdot\right\| g \|_{X} \cdot\right.
$$


Since $K$ is assumed continuous at $t=0$ and $t=1$, there are values for $a$ and $b$ sufficiently near, but distinct from 0 and 1 respectively, such that each of $W_{0}^{a} K$ and $W_{b}^{1} K$ less than $\varepsilon / 8 M[1+\|g\|]$. With these values of $a$ and $b$, there is $n$ sufficiently large, by the above lemma, that

$$
\max _{a \leqq t \leqq b}\left\|\sum_{k=0}^{n}\left(\begin{array}{c}
n \\
k
\end{array}\right) t^{k}(1-t)^{n-k}\left[V^{k} g-V^{k+1} g\right]\right\|_{x} \leqq \varepsilon / 2\left[1+W_{a}^{b} K\right] .
$$

Collecting all this together yields

$$
\left\|T_{n} f\right\|_{Y} \leqq \varepsilon
$$

for all $n$ sufficiently large. Thus

$$
\lim _{n \rightarrow \infty}\left\|T_{n} f\right\|_{Y}=\lim _{n \rightarrow \infty}\left\|T_{n} f-L P f\right\|=0
$$

since

$$
L P f=\theta_{Y}
$$

and this completes the proof.

In case that $Y \equiv X$ and $H$ is regular relative to $I$, then $H$ sums $\left\{V^{k}\right\}_{k=0}^{\infty}$ to $P$. In particular, any regular scalar-valued Hausdorff method whose generating function $K$ is continuous at $t=0$ and $t=1$ will sum $\left\{V^{k}\right\}_{k=0}^{\infty}$ to $P$. The case treated in [2], corresponds to the case here where $K(t)=t I$, i.e., the $C_{1}$ method. The following example illustrates the theorem for a nonscalar-valued Hausdorff method.

Suppose $X=Y=H$, a Hilbert space. Suppose also that $K$ is a bounded resolution of the identity such that $K(0)=0, K(1)=I, K$ is continuous at 0 and 1 in the operator norm, and $K$ satisfies the Gowurin $\omega$-property. The approximating sums for integrals of the form $\int_{0}^{1} t^{n} d K(t)$ converge to the integral in the operator norm [2], hence they converge in the sense given by Tucker [3]. Consider the moment sequence $\left\{\mu_{n}\right\}_{n=0}^{\infty}$ given by $\mu_{n}=\int_{0}^{1} t^{n} d K(t)$. As shown in [2], $\mu_{1}$ is a selfadjoint operator in $H$, and if we denote it by $A$, it follows that $\mu_{n}=A^{n}(n=0,1,2, \cdots)$ where $\mu_{0}=K(1)=A^{0}=I$. If $\left\{V^{n}\right\}_{n=0}^{\infty}$ is a sequence of operators as given in the theorem, and $H(\mu)$ is the Hausdorff summability method generated by $\left\{\mu_{n}\right\}=\left\{A^{n}\right\}$, then

$$
\lim _{n \rightarrow \infty} \sum_{k=0}^{n}\left(\begin{array}{c}
n \\
k
\end{array}\right)\left(\Delta^{n-k} A^{k}\right) V^{k} x=P x
$$

for all $x \in H$, the limit being taken in the norm of $H$. 


\section{PART 2}

It has been pointed out that the proof of the lemma given above is incorrect. It can be corrected in the following manner. As given,

$$
\left\|A_{n}(t)\right\|_{s} \leqq \frac{N^{\prime}}{t} \sum_{k=0}^{n}\left(\left(\begin{array}{l}
n \\
k
\end{array}\right) t^{k}(1-t)^{n-k} \frac{\left|t-\frac{k}{n+1}\right|}{1-\frac{k}{n+1}}\right)+t^{n} N^{\prime} .
$$

Proceed as follows. For $0<a \leqq t \leqq b<1$

$$
\left\|A_{n}(t)\right\|_{s} \leqq \frac{N^{\prime}}{a} \sum_{k=0}^{n}\left(\begin{array}{l}
n \\
k
\end{array}\right) t^{k}(1-t)^{n-k} \frac{\left|t-\frac{k}{n+1}\right|}{1-\frac{k}{n+1}}+b^{n} N^{\prime} .
$$

Suppose $\varepsilon>0$ and pick $\delta$ such that $0<\delta<\{(1-b) \varepsilon / 2 /(1+\varepsilon \mid 2)\}$. For $t \in[a, b]$, set

$$
A_{t}=\left\{k:\left|t-\frac{k}{n+1}\right|<\delta\right\} \quad \text { and } \quad B_{t}=\left\{k:\left|t-\frac{k}{n+1}\right| \geqq \delta\right\} .
$$

Then

$$
\begin{aligned}
& \sum_{k=0}^{n}\left(\begin{array}{l}
n \\
k
\end{array}\right) t^{k}(1-t)^{n-k} \frac{\left|t-\frac{k}{n+1}\right|}{1-\frac{k}{n+1}} \\
&=\left(\sum_{A_{t}}+\sum_{B_{t}}\right)\left\{\left(\begin{array}{c}
n \\
k
\end{array}\right) t^{k}(1-t)^{n-k} \frac{\left|t-\frac{k}{n+1}\right|}{1-\frac{k}{n+1}}\right\} .
\end{aligned}
$$

Consider the sums separately.

$$
\begin{gathered}
\sum_{A_{t}} \leqq \sum_{A_{t}}\left(\begin{array}{c}
n \\
k
\end{array}\right) t^{k}(1-t)^{n-k} \frac{\delta}{1-b-\delta} \leqq \sum_{k=0}^{n}\left(\begin{array}{c}
n \\
k
\end{array}\right) t^{k}(1-t)^{n-k} \frac{\varepsilon}{2}=\frac{\varepsilon}{2} . \\
\sum_{B_{t}}=\frac{1}{1-t} \sum_{B_{t}}\left(\begin{array}{c}
n \\
k
\end{array}\right) \frac{n+1}{n+1-k} t^{k}(1-t)^{n-k+1}\left|t-\frac{k}{n+1}\right| .
\end{gathered}
$$

For $k \in B_{t}$,

$$
\left|\frac{k}{n+1}-t\right| \leqq 1 \leqq \frac{((n+1) t-k)^{2}}{\delta^{2}(n+1)^{2}}
$$




$$
\begin{aligned}
\sum_{B_{t}} & \leqq \frac{1}{(1-t) \delta^{2}(n+1)^{2}} \sum_{k=0}^{n}\left(\begin{array}{c}
n \\
k
\end{array}\right) \frac{n+1}{n+1-k} t^{k}(1-t)^{n-k+1}[(n+1) t-k]^{2} \\
& =\frac{1}{(1-t) \delta^{2}(n+1)^{2}} \sum_{k=0}^{n+1}\left(\begin{array}{c}
n+1 \\
k
\end{array}\right) t^{k}(1-t)^{n-k+1}[(n+1) t-k]^{2} \\
& =\frac{1}{(1-t) \delta^{2}} \sum_{k=0}^{n+1}\left(\begin{array}{c}
n+1 \\
k
\end{array}\right) t^{k}(1-t)^{n-k+1}\left(t-\frac{k}{n+1}\right)^{2} \\
& =\frac{1}{(1-t) \delta^{2}} \cdot \frac{t(1-t)}{n+1} \leqq \frac{b}{(n+1) \delta^{2}} .
\end{aligned}
$$

Collecting this together gives

$$
\left\|A_{n}(t)\right\|_{s} \leqq \frac{N^{\prime}}{a}\left(\frac{\varepsilon}{2}+\frac{b}{(n+1) \delta^{2}}+b^{n} N^{\prime}, \quad \text { for } 0<a \leqq t \leqq b<1,\right.
$$

which proves the lemma.

\section{BIBLIOGRAPHY}

1. L. C. Kurtz and D. H. Tucker, Vector-valued summability methods on a linear normed space, Proc. Amer. Math. Soc. 16 (1965), 419-428.

2. E. R. Lorch, Spectral Theory, Oxford University Press, New York, 1962.

3. D. H. Tucker, A representation theorem for a continuous linear transformation on a space of continuous functions, Proc. Amer. Math. Soc. 16 (1965), 946-953.

Received July 12, 1967. This research was done while the authors were participating in the ARMU Differential Equations Symposium in Boulder, Colorado.

ARIzona State University AND

UNIVERSITY OF UTAH 



\section{PACIFIC JOURNAL OF MATHEMATICS}

\section{EDITORS}

\section{H. ROYDEN}

Stanford University

Stanford, California

\section{J. Dugundu}

Department of Mathematics University of Southern California Los Angeles, California 90007

RICHARD ARENS

University of California Los Angeles, California 90024

ASSOCIATE EDITORS
E. F. Beckenbach
B. H. NEUMANN
F. WoLF
K. YosidA

\section{SUPPORTING INSTITUTIONS}

\author{
UNIVERSITY OF BRITISH COLUMBIA \\ CALIFORNIA INSTITUTE OF TECHNOLOGY \\ UNIVERSITY OF CALIFORNIA \\ MONTANA STATE UNIVERSITY \\ UNIVERSITY OF NEVADA \\ NEW MEXICO STATE UNIVERSITY \\ OREGON STATE UNIVERSITY \\ UNIVERSITY OF OREGON \\ OSAKA UNIVERSITY \\ UNIVERSITY OF SOUTHERN CALIFORNIA
}

STANFORD UNIVERSITY

UNIVERSITY OF TOKYO

UNIVERSITY OF UTAH

WASHINGTON STATE UNIVERSITY

UNIVERSITY OF WASHINGTON

AMERICAN MATHEMATICAL SOCIETY
CHEVRON RESEARCH CORPORATION
TRW SYSTEMS

AMERICAN MATHEMATICAL SOCIETY

TRW SYSTEMS

NAVAL WEAPONS CENTER

Mathematical papers intended for publication in the Pacific Journal of Mathematics should be in typed form or offset-reproduced, double spaced with large margins. Underline Greek letters in red, German in green, and script in blue. The first paragraph or two must be capable of being used separately as a synopsis of the entire paper. It should not contain references to the bibliography. Manuscripts, in duplicate if possible, may be sent to any one of the four editors. All other communications to the editors should be addressed to the managing editor, Richard Arens, University of California, Los Angeles, California 90024.

Each author of each article receives 50 reprints free of charge; additional copies may be obtained at cost in multiples of 50 .

The Pacific Journal of Mathematics is published monthly. Effective with Volume 16 the price per volume (3 numbers) is $\$ 8.00$; single issues, $\$ 3.00$. Special price for current issues to individual faculty members of supporting institutions and to individual members of the American Mathematical Society: $\$ 4.00$ per volume; single issues $\$ 1.50$. Back numbers are available.

Subscriptions, orders for back numbers, and changes of address should be sent to Pacific Journal of Mathematics, 103 Highland Boulevard, Berkeley 8, California.

Printed at Kokusai Bunken Insatsusha (International Academic Printing Co., Ltd.), 7-17, Fujimi 2-chome, Chiyoda-ku, Tokyo, Japan.

PUBLISHED BY PACIFIC JOURNAL OF MATHEMATICS, A NON-PROFIT CORPORATION

The Supporting Institutions listed above contribute to the cost of publication of this Journal, but they are not owners of publishers and have no responsibility for its content or policies. 


\section{Pacific Journal of Mathematics \\ Vol. 27, No. 3}

March, 1968

Charles A. Akemann, Invariant subspaces of $C(G) \ldots \ldots \ldots \ldots \ldots \ldots . \ldots 41$

Dan Amir and Zvi Ziegler, Generalized convexity cones and their duals ... . 425

Raymond Balbes, On ( $J, M, \mathrm{~m})$-extensions of order sums of distributive

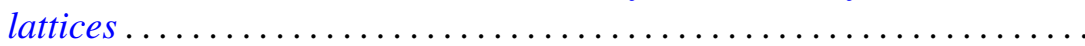

Jan-Erik Björk, Extensions of the maximal ideal space of a function algebra ........................................ 453

Frank Castagna, Sums of automorphisms of a primary abelian group ...... 463

Theodore Seio Chihara, On determinate Hamburger moment problems ..... .

Zeev Ditzian, Convolution transforms whose inversion function has complex

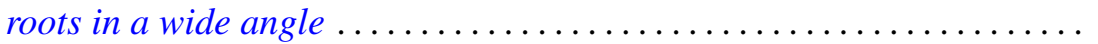

Myron Goldstein, On a paper of Rao .

Velmer B. Headley and Charles Andrew Swanson, Oscillation criteria for

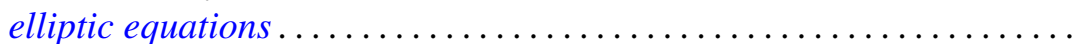

John Willard Heidel, Qualitative behavior of solutions of a third order nonlinear differential equation............................

Alan Carleton Hindmarsh, Pick's conditions and analyticity.............

Bruce Ansgar Jensen and Donald Wright Miller, Commutative semigroups

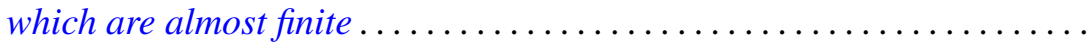

Lynn Clifford Kurtz and Don Harrell Tucker, An extended form of the

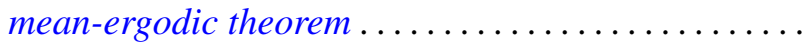

S. P. Lloyd, Feller boundary induced by a transition operator ...

Henry B. Mann, Josephine Mitchell and Lowell Schoenfeld, A new proof of the maximum principle for doubly-harmonic functions ...

Robert Einsohn Mosher, The product formula for the third obstruction ..

Sam Bernard Nadler, Jr., Sequences of contractions and fixed points ...

Eric Albert Nordgren, Invariant subspaces of a direct sum of weighted shifts...

Fred Richman, Thin abelian p-groups ...

Jordan Tobias Rosenbaum, Simultaneous interpolation in $\mathrm{H}_{2}$. II ...

Charles Thomas Scarborough, Minimal Urysohn spaces .

Malcolm Jay Sherman, Disjoint invariant subspaces..... .

Joel John Westman, Harmonic analysis on groupoids....

621

William Jennings Wickless, Quasi-isomorphism and TFM

Minoru Hasegawa, Correction to "On the convergence of resolvents of operators" 